\title{
ANALISIS KEPUASAN MASYARAKAT TERHADAP LAYANAN LISTRIK PRABAYAR
}

\author{
Oleh: \\ Iryati Nur Nofiana \\ Staff PT. Bank Rakyat Indonesia (Persero) Tbk. \\ E-mail/No. Hp: ovy_nur@gmail.com/-
}

\begin{abstract}
The research objective is to find out how much public response to the electrical system of prepaid payment services in PT PLN (Persero) Mojokerto District, to know the standards of good service to the community performed by employees in PT PLN (Persero). Analysis tools used in this study using public indeks and SWOT analysis. Analytical results obtained are the payment service user respondents answer pre-paid electricity system in PT PLN (Persero) Mojokerto District. Based on this research, the implications of this study from all the answers given by respondents to the researcher, that the services provided by PT PLN (Persero) relating to the standards of public service include speed, accuracy, and cost of the prepaid electricity system in a state of very satisfied and deserve to be retained, while for public response to give service quality, respondens expressed very satisfied and deserve to be preserved.
\end{abstract}

Keywords: service quality, public service, good service.

\begin{abstract}
Abstrak
Tujuan penelitian ini adalah untuk mengetahui seberapa besar respon masyarakat terhadap sistem listrik prabayar layanan pembayaran di PT PLN (Persero) Kabupaten Mojokerto, serta untuk mengetahui standar pelayanan yang baik kepada masyarakat yang dilakukan oleh karyawan di PT PLN (Persero). Alat analisis yang digunakan dalam penelitian ini menggunakan indeks kepuasan masyarakat dan analisa SWOT. Hasil analisis yang diperoleh adalah responden pengguna layanan pembayaran menjawab pra-bayar sistem kelistrikan di PT PLN (Persero) Kabupaten Mojokerto. Berdasarkan hasil penelitian ini, implikasi dari penelitian ini dari semua jawaban yang diberikan oleh responden kepada peneliti, bahwa layanan yang diberikan oleh PT PLN (Persero) terkait dengan standar pelayanan publik meliputi kecepatan, ketepatan, dan biaya dari sistem listrik prabayar dalam keadaan sangat puas dan pantas untuk dipertahankan, sedangkan untuk respon masyarakat terhadap kualitas layanan yang diberikan, responden menyatakan sangat puas dan layak untuk dipertahankan.
\end{abstract}

Kata Kunci: service quality, pelayanan publik, pelayanan yang baik. 


\section{PENDAHULUAN}

Saat ini kebutuhan energi listrik untuk kebutuhan rumah tangga dan industri pada umumnya dipenuhi oleh PT.PLN (Persero), karena PT.PLN (Persero) adalah Badan Usaha milik Negara (BUMN) yang ditunjuk sebagai penyedia layanan listrik di Indonesia. Listrik merupakan kebutuhan pokok bagi kehidupan manusia. Ketergantungan manusia akan listrik terjadi karena energi tersebut sangat fleksibel, sehingga dapat dengan mudah diubah menjadi energi dalam bentuk lain untuk menggerakkan peralatan industri, rumah tangga dan lain sebagainya.

Produktivitas PT.PLN (Persero) merupakan kemampuan perusahaan jasa dalam menggunakan input untuk menyediakan jasa dengan memenuhi ekspektasi pelanggan. Untuk itu PT.PLN dituntut untuk lebih keras lagi dalam mengupayakan kebutuhan listrik pelanggannya terpenuhi, sehingga keluhan-keluhan yang selama ini diutarakan oleh pelanggan bisa teratasi dalam kondisi yang sedang krisis listrik ini. Dari keluhankeluhan tersebut maka PT.PLN mempunyai upaya untuk mengatasinya yaitu dengan inovasi terbaru yaitu pelayanan listrik dengan sistem prabayar.

Sistem prabayar ini sudah dimulai sekitar tahun 2009, namun sampai sekarang PLN masih belum bisa melayani pelanggan seluruh Indonesia, karena terbatasnya kesiapan pabrikan dalam negeri dalam menyediakan meter prabayar.

Layanan listrik prabayar merupakan bentuk pelayanan PLN dalam menjual energi listrik dengan cara pelanggan membayar dimuka. Yaitu pelanggan terlebih dahulu membeli sejumlah nominal energi listrik sesuai dengan yang dibutuhkan. Dengan cara ini pengendalian pemakaian listrik sepenuhnya pada pelanggan.

Dengan cara seperti ini, pelanggan tidak perlu khawatir lagi dengan tagihan listrik yang membengkak, kesalahan pembaca meteran yang membebani pelanggan, serta pemutusan listrik yang secara tiba-tiba apabila telat untuk membayar. Dengan sistem prabayar ini, hal-hal yang tidak diinginkan tidak akan terjadi lagi, sehingga antara pelanggan dan PLN mempunyai hubungan yang baik. Selain itu pula masyarakat pengguna 
listrik bisa lebih berhemat dalam pemakaian listrik setiap harinya, karena listrik prabayar ini secara tidak langsung dapat mengajak para masyarakat berhemat dalam menggunakan listrik, karena kontrol pemakaian sepenuhnya berada pada pelanggan (masyarakat).

Sebagaimana telah diuraikan sebelumnya bahwa kualitas pelayanan menjadi semakin penting bagi organisasi-organisasi penghasil layanan. Gronroos: 1984 dalam Durisandi Cardinalia, Manda (2010) mengusulkan dua tipe kualitas pelayanan, yaitu teknikal dan fungsional (technical and functional) dimana keduanya memberikan kontribusi kepada kualitas pelayanan yang dirasakan (perceived service quality). Technical quality sering dapat dinilai dalam kondisi obyektif, sedangkan functional quality dirasakan melalui cara yang lebih subyektif. Technical quality misalnya transfer uang dari satu rekening bank ke rekening bank yang lain, sedangkan functional quality misalnya sikap, aksesibilitas, penampilan sebuah instansi. Dipihak lain Peters dan Waterman maupun Lassem membagi kualitas pelayanan ke dalam hard and soft quality (dalam Gabott \& Hog, 1997). Hard quality meliputi strategi, struktur, dan sistem organisasi. Sedangkan soft quality diantaranya meliputi skill, staff atau style. Hand and quality mempengaruhi perjalanan hari demi hari suatu hubungan dan keduanya mempengaruhi satu dan yang lainnya.

$$
\text { Menurut Munir }
$$

pelayanan adalah aktivitas yang dilakukan seseorang atau kelompok orang dengan landasan faktor material melalui sistem, prosedur, dan metode tertentu dalam rangka memenuhi kebutuhan-kebutuhan orang lain sesuai dengan haknya. Hal ini menunjukkan bahwa pelayanan adalah salah satu bentuk sistem, prosedur atau metode tertentu yang diberikan kepada orang lain, dalam hal ini agar kebutuhan pelanggan dapat terpenuhi sesuai dengan harapan mereka.

Pemerintah memiliki peran yang sangat besar dalam pembuatan program pelayanan dan kebijakan publik. Berbagai kebijakan dan peraturan yang menyangkut organisasi layanan publik dirumuskan dengan mempertimbangkan kebutuhan publik, tanggung jawab 
pemerintah tidak sekedar membuat dan menjalankan program yang bernilai ekonomis, namun yang lebih penting justru identifikasi apakah program dari kebijkan tersebut sudah sesuai dengan keinginan publik atau belum, atau malah membatasi ruang gerak masyarakat untuk bisa berkreasi secara produktif. Tingkat kehidupan masyarakat secara pribadi diharapkan bisa bertambah baik dan maju atas kebijakan pemerintah yang ditetapkan tersebut.

Agar mengetahui tingkat kepuasan masyarakat diperlukan menghitung indeks kepuasan masyarakat. Indeks kepuasan masyarakat adalah data dan informasi tentang tingkat kepuasan masyarakat yang diperoleh dari hasil pengukuran secara kuantitatif dan kualitatif atas pendapat masyarakat dalam memperoleh pelayanan dari aparatur penyelenggara pelayanan publik dengan membandingkan antara harapan dan kebutuhannya.

\section{METODE PENELITIAN}

Penelitian ini dilakukan pada PT.PLN (Persero) Unit Pelayanan Jaringan Kecamatan Puri-Kabupaten Mojokerto. Data-data primer yang diperoleh dengan cara penyebaran kuesioner yang telah diisi oleh pelanggan listrik yang menggunakan listrik prabayar. Alasan memilih lokasi penelitian di Kecamatan PuriKabupaten Mojokerto karena mayoritas penduduk Kecamatan Puri menggunakan listrik dengan sistem prabayar, sehingga data yang diperlukan menjadi akurat.

Berdasarkan cara memperoleh data, penulis menggunakan data primer dan sekunder. Data primer yaitu dimana peneliti mengumpulkan, mengolah, dan menyebarkan kuesioner kepada masyarakat responden pengguna pelayanan pembayaran listrik sistem pra bayar yang menggunakan daya 900 Va. Sedangkan data sekunder adalah diperoleh dari pihak yang bersifat saling melengkapi dengan data primer. Yang termasuk data sekunder dalam penelitian ini yaitu yang diperoleh secara langsung dari obyek penelitian ini yaitu melalui dokumentasi data yang diperoleh dari PT.PLN (Persero) Kabupaten Mojokerto.

Populasi pada penelitian ini adalah semua pelanggan listrik yang menggunakan jasa pelayanan 
pembayaran listrik dengan sistem prabayar di PT.PLN (Persero) Kecamatan Puri Kabupaten Mojokerto yang menggunakan daya $900 \mathrm{Va}$, dimana populasi yang ada yaitu sebanyak 441 pelanggan.

Adapun sampel dalam penelitian ini merupakan bagian dari populasi, yang dijadikan sampel dalam penelitian ini adalah pengguna atau masyarakat yang memanfaatkan jasa pelayanan sistem prabayar pada PT.PLN (Persero) Kecamatan Puri Kabupaten Mojokerto. Dalam pengambilan sampel ini digunakan metode purposive sampling.

Teknik pengambilan sampel yang digunakan adalah teknik purposive sampling yaitu teknik pengambilan sampel sesuai dengan tujuan, dimana peneliti mengambil di sebagian wilayah/daerah Kecamatan Puri dengan melihat beberapa kriteria yang sengaja dibuat oleh peneliti. mayoritas penduduk Kecamatan Puri Kabupaten Mojokerto menggunakan jasa pembayaran listrik prabayar dibandingkan dengan penduduk di Kecamatan-kecamatan yang ada di Kabupaten Mojokerto, sehingga peneliti menggunakan teknik tersebut. Sampel yang diambil oleh peneliti sebanyak 60 pelanggan dimana pelanggan tersebut adalah yang memakai listrik dengan daya $900 \mathrm{Va}$. Alasan memilih pelanggan yang menggunakan daya $900 \mathrm{Va}$ adalah karena penelitian ini dikhususkan untuk meneliti pemakaian listrik dalam kategori rumah tangga

Teknik Analisa Data dalam penelitian ini adalah Indeks Kepuasan Masyarakat dengan ketentuan sebagaimana pada tabel 1. Adapun analisis yang kedua yaitu menggunakan Analisa SWOT. Adapun Gambar Matriks SWOT dapat dilihat pada gambar 1 .

Pertimbangan tersebut adalah karena

Tabel 1. Nilai Persepsi, Interval IKM, Interval Konversi IKM, Mutu Pelayanan dan Tingkat Kepuasan

\begin{tabular}{ccccc}
\hline $\begin{array}{c}\text { Nilai } \\
\text { Persepsi }\end{array}$ & $\begin{array}{c}\text { Nilai } \\
\text { Interval IKM }\end{array}$ & $\begin{array}{c}\text { Nilai } \\
\text { Interval } \\
\text { Konversi IKM }\end{array}$ & $\begin{array}{c}\text { Mutu } \\
\text { Layanan }\end{array}$ & $\begin{array}{c}\text { Tingkat } \\
\text { Kepuasan }\end{array}$ \\
\hline 1 & $1,00-1,75$ & $25-43,75$ & D & Tidak puas \\
2 & $1,76-2,50$ & $43,76-62,50$ & C & Kurang puas \\
3 & $2,51-3,25$ & $62,51-81,25$ & B & Cukup puas \\
4 & $3,26-4,00$ & $81,26-100,00$ & A & Sangat puas \\
\hline
\end{tabular}

Sumber : Data diolah 


\section{Gambar 1. Analisis SWOT}

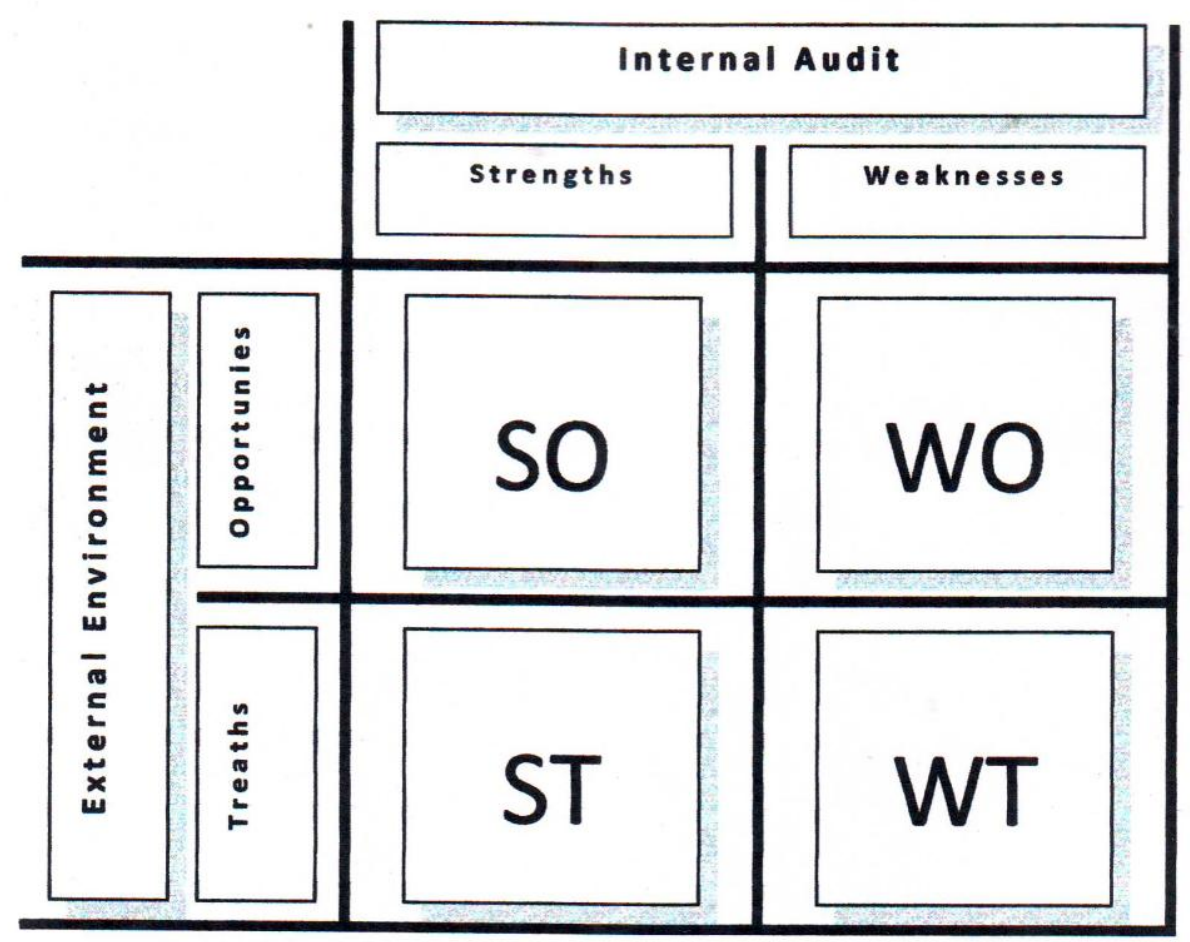

Sumber: Wicaksono \& Sugiarto, 2001

\section{PEMBAHASAN}

Setelah menganalisis indikatorindikator kinerja pelayanan di atas, berikut ini akan dianalisis indeks kepuasan masyarakat (IKM) atas pelayanan pembayaran listrik sistem prabayar di Kecamatan Puri Kabupaten Mojokerto secara keseluruhan. Analisis ini dapat dilakukan dengan cara menghitung nilai indeks dari unit pelayanan kinerja secara keseluruhan, adapun nilai indeks dapat diperoleh dengan cara mengalikan masing-masing nilai ratarata unsur dengan bobot nilai rata-rata tertimbang lalu dikalikan dengan nilai dasar.

Berdasarkan tabel 2, maka untuk mengetahui nilai indeks unit pelayanan dihitung dengan cara sebagai berikut: $(3,43 \times 0,125)+$ $(3,56 \times 0,125)+(3,32 \times 0,125)+$ $(3,45 \times 0,125)+(3,39 \times 0,125)+$ $(3,53 \times 0,125)+(3,56 \times 0,125)+$ $(3,59 \times 0,125)=3,49$. Dengan demikian nilai indeks unit pelayanan hasilnya dapat dijelaskan yaitu Nilai IKM setelah dikonversi dari

Nilai Indeks x Nilai Dasar $(3,49$ x 25), hasilnya sebesar 87,25 . 
Sebagaimana kriteria yang pelayanan pembayaran listrik disampaikan pada metode penelitian, Kabupaten Mojokerto maka maka hasil tersebut menunjukkan diperlukan suatu analisis untuk mutu tingkat kepuasan pelayanan melihat potensi dan masalah yang ada adalah A, atau tingkat kepuasan pada sistem prabayar PT.PLN masyarakat adalah Sangat Puas.

Adapun nilai indeks secara (Persero) Kabupaten Mojokerto. keseluruhan diperoleh angka indeks Berikut ini adalah analisis SWOT sebesar 87,25. Dengan demikian untuk sistem prabayar PT.PLN tingkat kepuasan masyarakat di (Persero) Kabupaten Mojokerto yakni Kecamatan Puri Kabupaten Mojokerto dilihat dari seluruh indikator yang ada menyatakan sangat puas.

Sedangkan untuk mengetahui pelayanan publik khususnya pada mengenai pelayanan publik yang berada di Kecamatan Puri. Hal ini dikarenakan Kecamatan Puri merupakan daerah yang paling dominan dalam menggunakan jasa Tabel 2. Nilai Rata-Rata Unsur Dan Masing-Masing Unit Pelayanan

\begin{tabular}{clc}
\hline No & \multicolumn{1}{c}{ Unsur Pelayanan } & $\begin{array}{c}\text { Nilai Unsur } \\
\text { Pelayanan }\end{array}$ \\
\hline 1 & Prosedur Pelayanan & 3,43 \\
2 & Persyaratan Pelayanan & 3,56 \\
3 & Kejelasan dan Tanggungjawab Petugas Pelayanan & 3,32 \\
4 & Kedisiplinan dan Kecepatan Pelayanan & 3,45 \\
5 & Kemampuan Petugas Pelayanan & 3,39 \\
6 & Keadilan Mendapatkan Pelayanan & 3,53 \\
7 & Kesopanan dan Keramahan Petugas & 3,56 \\
8 & Kewajaran dan Kepastian Biaya & 3,59 \\
\hline
\end{tabular}

Sumber : Data dioalah 
Tabel 3. Analisis Matriks SWOT Listrik Sistem Prabayar di Kecamatan Puri-Kabupaten Mojokerto

FAKTOR

EKSTERNAL

1. Keluhan-keluhan dari pelanggan

FAKTOR

INTERNAL

\section{Opportunity}

. Tagihan bulanan semakin naik, sehingga dengan prabayar ini pelanggaan bisa mengendalikan

pemakaian listriknya
3. Prabayar adalah produk baru, harus ada inovasi agar konsumen tidak beralih ke listrik pasca bayar
Threat

4. Masih terbatasnya jumlah meteran prabayar, sehingga pelanggan cenderung memilih produk lama yang sudah dipercaya, yaitu listrik pasca bayar

\begin{tabular}{|c|c|c|c|}
\hline & Strenght & STRATEGI S-O & STRATEGI S-T \\
\hline 1 & $\begin{array}{l}\text { Mudah } \\
\text { mengoptimalkan } \\
\text { listrirk }\end{array}$ & $\begin{array}{l}\text { 1. Dengan listrik prabayar, maka pelanggan bisa } \\
\text { lebih mudah mengoptimalkan listrik, sehingga } \\
\text { pelanggan bisa mengendalikan pemakaian }\end{array}$ & $\begin{array}{l}\text { 1. Persediaan kwh dapat ditambah berapa dan kapan } \\
\text { saja sesuai kebutuhan, tetapi masih terbatasnya } \\
\text { meteran prabayar, sehingga pelanggan cenderung }\end{array}$ \\
\hline 2 & Tidak ada catatan & listriknya. (S-1, O-2) & lebih memilih produk lama yaitu pasca bayar. (S- \\
\hline 3 & $\begin{array}{l}\text { meter per bulan } \\
\text { Tidak terikat } \\
\text { dengan jadwal } \\
\text { pembayaran }\end{array}$ & $\begin{array}{l}\text { 2. Pelanggan tidak perlu berurusan dengan } \\
\text { pencatatan meteran setiap bulannya karena } \\
\text { pengendalian pemakaian listrik sepenuhnya } \\
\text { pada pelanggan. }(\mathrm{S}-2, \mathrm{O}-2)\end{array}$ & $\begin{array}{l}\text { 4, T-2) } \\
\text { Pelaksanaan penyambungan cepat tetapi apabila PT. } \\
\text { PLN tidak melakukan inovasi-inovasi terhadap } \\
\text { produk prabayar maka pelanggan cenderung }\end{array}$ \\
\hline 4 & $\begin{array}{l}\text { bulanan } \\
\text { Persedian kwh } \\
\text { dapat ditambah } \\
\text { berapa saja dan }\end{array}$ & $\begin{array}{l}\text { 3. Pelanggan tidak perlu terikat dengan jadwal } \\
\text { pembayaran bulanan sehingga keluhan-keluhan } \\
\text { karena membengkaknya tagihan rekening listrik } \\
\text { oleh pelanggan bisa diminimalisir. }(\mathrm{S}-3, \mathrm{O}-1)\end{array}$ & $\begin{array}{l}\text { kembali memakai produk lama yaitu pasca bayar. } \\
(\mathrm{S}-13, \mathrm{~T}-1)\end{array}$ \\
\hline & $\begin{array}{l}\text { kapan saja sesuai } \\
\text { kebutuhan }\end{array}$ & $\begin{array}{l}\text { 4. Kontrol pemakaian sepenuhnya ditangan } \\
\text { pelanggan, sehingga keluhan-keluhan }\end{array}$ & \\
\hline 5 & $\begin{array}{l}\text { Kontrol } \\
\text { pemakaian di }\end{array}$ & $\begin{array}{l}\text { pelanggan mengenai kesalahan pembaca meter } \\
\text { tidak ada. }(\mathrm{S}-5, \mathrm{O}-1)\end{array}$ & \\
\hline 6 & $\begin{array}{l}\text { pelanggan } \\
\text { Lebih terbuka dan } \\
\text { transparan }\end{array}$ & $\begin{array}{l}\text { 5. Pelanggan dapat mengendalikan listrik sesuai } \\
\text { anggaran belanja sehigga tidak ada keluhan- } \\
\text { keluhan pelanggan akibat tagihan listrik yang }\end{array}$ & \\
\hline 7 & $\begin{array}{l}\text { Pelanggan bisa } \\
\text { memantau } \\
\text { pemakaian per }\end{array}$ & $\begin{array}{l}\text { membengkak. }(\mathrm{S}-8, \mathrm{O}-1) \\
\text { 6. Privasi pelanggan tidak terganggu, karena } \\
\text { pelanggan yang mengendalikan pemakaian }\end{array}$ & \\
\hline
\end{tabular}




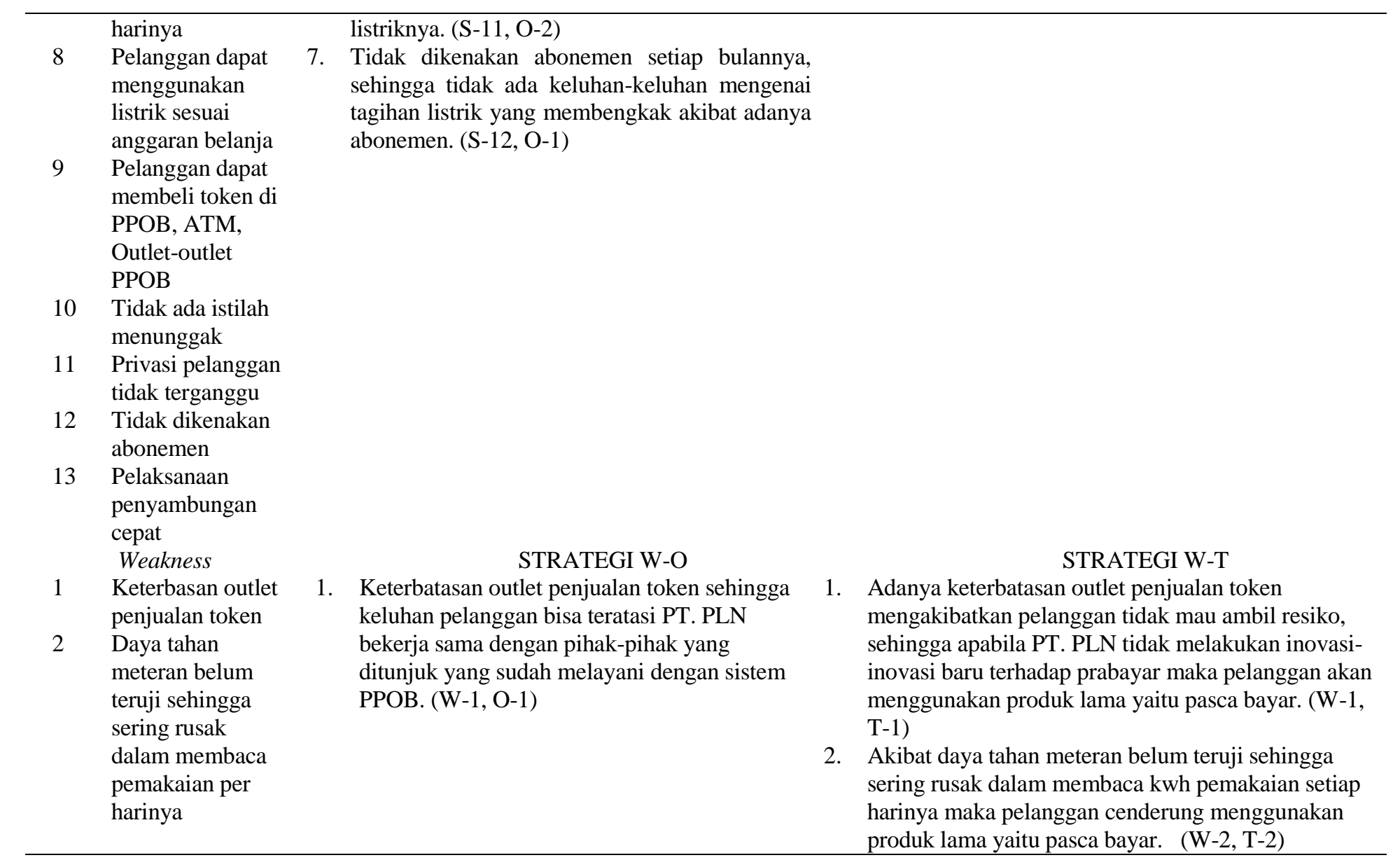

Sumber : Data Diolah 
Berdasarkan tabel 3, diketahui Kekuatan Sistem Prabayar. Adapun kekuatan dari listrik sistem prabayar adalah sebagai berikut: 1) Pelanggan bisa lebih mudah mengoptimalkan konsumsi listrik; 2) Pelanggan tidak perlu berurusan dengan pencatatan meter setiap bulan; 3) Pelangan tidak perlu terikat dengan jadwal pembayaran listrik bulanan, karena persediaan $\mathrm{kWh}$ dapat ditambah berapa saja dan kapan saja sesuai kebutuhan dan keinginan pelanggan;

4) Kontrol pemakaian di tangan pelanggan; 5) Lebih terbuka dan transparan; 6) Pelanggan dapat dengan mudah memantau pemakaian listriknya setiap saat; 7) Pelanggan dapat mendisiplinkan diri sendiri untuk menggunakan listrik sesuai anggaran belanja; 8) Pelanggan dapat membeli token (isi ulang energi listrik) di payment point, ATM dengan jaringan yang luas dan outletoutlet PPOB; 9) Tidak ada istilah menunggak; 10) Privasi pelanggan tidak terganggu; 11) tidak dikenakan abonemen setiap bulannya; dan 12) Pelaksanaan penyambungan cepat.

Adapun kelemahan dari listrik sistem prabayar adalah sebagai berikut: 1) Keterbatasan outlet penjualan voucher, dan akan sangat repot jika pulsa habis di malam hari; 2) Masih diberlakukannya pemadaman bergilir sewaktu-waktu tanpa adanya pemberitahuan terlebih dahulu kepada masyarakat.

Adapun peluang dari listrik sistem prabayar adalah sebagai berikut: 1) Adanya keluhan-keluhan masyarakat akan seringnya salah dalam pencatatan meteran setiap bulannya mengakibatkan sistem prabayar ini diberlakukan; 2) Tagihan yang dirasa selalu naik setiap bulannya, sehingga dengan prabayar ini konsumen bisa mengendalikan sendiri pemakaian listrik serta sesuai dengan anggaran konsumen tersebut.

Sedangkan ancaman dari listrik sistem prabayar adalah sebagai berikut: 1) Prabayar merupakan produk baru, sehingga apabila pihak PT.PLN tidak melakukan inovasiinovasi terhadap produk ini maka konsumen cenderung akan kembali pada pascabayar; 2) Masih terbatasnya meteran yang belum disediakan oleh PT.PLN sehingga masyarakat cenderung menggunakan listrik pascabayar karena takut resiko tidak akan segera dipasang aliran listrik dirumah sehingga pelanggan 
cenderung memilih produk pasca bayar yang sudah terjamin akan segera teraliri listrik.

Dari hasil yang diperoleh peneliti, maka PT.PLN (Persero) mempunyai solusi kebijakan mengenai listrik sistem prabayar untuk jangka waktu yang akan datang, yaitu diharapkan seluruh konsumen bisa menggunakan listrik prabayar, karena dengan menggunakan prabayar diharapkan tidak ada lagi salah paham ataupun permasalahan-permasalahan yang terjadi antara pihak PT.PLN dengan konsumen akibat tagihan maupun kesalahan pencatatan meter setiap bulannya, karena dengan menggunakan prabayar ini maka kontrol listrik sepenuhnya ada pada pelanggan.

Hal-hal yang telah dilakukan oleh PT.PLN (Persero) berhubungan dengan memperkenalkan produk prabayar kepada konsumen yang masih menggunakan listrik pascabayar yang sudah sesuai dengan ketentuan Tarif Dasar Listrik (TDL) tahun 2010, antara lain: pertama, batas waktu pembayaran rekening listrik. Untuk setiap pembayaran rekening listrik pihak PT.PLN memberi batasan waktu dalam pembayaran, yaitu pada tanggal 20 setiap bulannya, dan pembayaran tersebut dapat dilakukan melalui seluruh loket-loket PPOB (Payment Point Online Bank), ATM, KUD, BANK, dll pihak yang ditunjuk oleh PT.PLN.

Kedua, pemutusan listrik. Setiap tanggal 21 bulan berjalan apabila pelanggan belum membayar atau melunasi rekening listrik maka dikenakan sanksi pemutusan sementara dan BK (Biaya Keuangan) pemutusan. Ketiga, pembongkaran rampung dan dikeluarkan dari data induk pelanggan (DIL). Sanksi tersebut berlaku apabila dalam jangka waktu 60 hari dari pemutusan sementara (tunggakan rekening 3 lembar/bulan) atau lebih, pelanggan belum melunasi tunggakan rekening listrik. Keempat, apabila setelah bongkar rampung pelanggan menghendaki untuk disambung kembali maka diberlakukan sebagai pelanggan baru dengan menggunakan listrik prabayar (LPB) dan harus melunasi seluruh tunggakan yang ada. 


\section{PENUTUP}

Berdasarkan penelitian yang telah dilakukan maka dapat diambil kesimpulan mengenai tingkat kepuasan masyarakat terhadap pelayanan pembayaran listrik sistem prabayar di Kecamatan Puri Kabupaten Mojokerto adalah sangat puas. Hal ini dapat dijelaskan bahwa tingkat kepuasan masyarakat terhadap pelayanan listrik sistem prabayar di Kecamatan Puri Kabupaten Mojokerto yang mencakup dalam 8 indikator sudah sangat puas, delapan indikator tersebut mencakup: prosedur pelayanan, persyaratan pelayanan, kejelasan dan tanggungjawab petugas pelayanan, kedisplinan dan kecepatan pelayanan, kemampuan petugas pelayanan, keadilan mendapatkan pelayanan, serta kewajaran dan kepastian biaya. Ini artinya pelayanan pembayaran listrik sistem prabayar tersebut sudah bisa memberikan pelayanan yang sangat baik terhadap masyarakat yang menggunakan listrik prabayar.

Berdasarkan hasil penelitian maka saran untuk listrik prabayar adalah sebagai berikut: 1) Memperbanyak outlet penjualan token untuk lebih mengutamakan pelanggannya; 2) Inovasi teknologi, yaitu dimungkinkannya pembayaran token secara online atau ATM; 3) Meningkatkan jumlah produksi meteran prabayar dan mengurangi meteran pasca bayar; 4) Meningkatkan kualitas produk prabayar, yaitu hendaknya lebih memperhatikan akan perawatan meteran sehingga tidak terjadinya kesalahan pembaca kwh pemakaian per harinya; 5) Memberikan penyuluhan dan promosi tentang kelebihan prabayar dibandingkan pasca bayar kepada masyarakat.

Sedangkan saran untuk masyarakat pengguna listrik prabayar adalah sebagai berikut: 1) Masyarakat diupayakan agar bisa berhemat dalam penggunaan listriknya; 2) Pemakaian setiap harinya harus selalu dikontrol, karena produk prabayar ini merupakan solusi terbaik dari PT.PLN dalam mengajak masyarakat berhemat dalam menggunakan listrik; dan 3) Kebutuhan pemakaian yang optimal lebih efisien lagi apabila menggunakannya sesuai dengan kebutuhan.

\section{DAFTAR PUSTAKA}

Anggita Rosmitha, Aisyah, 2011. "Tingkat

Kepuasan 
Pelayanan Publik Di Kecamatan Kedung Kandang Kota Malang"

Arikunto, S. 2006. Prosedur Penelitian: Suatu Pendekatan Praktik Edisi Revisi. Rineka Cipta: Jakarta

Bandung Sinambela Lijan Poltak dkk, 2002. Reformasi Pelayanan Publik (Teori, kebijakan, dan implementasi). Jakarta: PT. Bumi Aksara

Durisandi Cardinalia, Manda, 2010. "Dampak diberlakukannya sistim perkantoran

terpadu (Block Office)
terhadap pelayanan publik di
Kota Malang (studi pada
Badan Pelayanan Perijinan
Terpadu/BP2T dan Dinas
$\begin{aligned} & \text { Pencatatan } \\ & \text { Malang)" }\end{aligned}$

Iswardiningsih, Yeni, 2001. "Analisa Yang Mempengaruhi Permintaan Jasa Pemasangan Telepon Pada Rumah Tangga di Kecamatan Sumberpucung Kabupaten Malang"

Keputusan Menteri Pendayagunaan Aparatur Negara (MenPAN) Nomor 63/7/2003. Prinsipprinsip Pelayanan Publik

Keputusan Menteri Pendayagunaan Aparatur Negara (MenPAN) Nomor 81/1995. Sendi-sendi Pelayanan yang Berkualitas

Keputusan Menteri Nomor 81/1993. Aspek-aspek yang Mempengaruhi Pelayanan yang Tepat Sasaran
Nuril Nugraha, David, 2009. "Analisis Perkembangan Sektor Pariwisata di Kabupaten Mojokerto"

Raihan, 2007. "Kinerja Pelayanan Publik Sektor Pendidikan dan Sektor Kesehatan dalam Mewujudkan Tata Pemerintahan yang Baik atau Good Governance (Studi Kasus Pada Pemerintahan Kabupaten Barito Kuala)"

Rangkuti, Freddy, 2003. Analisis SWOT Teknik Mebedah Kasus Bisnis. Jakarta: PT. Gramedia Pustaka Utama

Santosa Panji, 2008. Administrasi Publik (Teori dan Aplikasi Good Governance). Bandung: PT. Refika Aditama Bandung

Supran, Eko. Analisis Pelayanan Publik Di Kota Malang (Studi di Dinas Kependudukan dan Catatan Sipil Kota Malang)

Ulum, 2005. "Akuntansi Sektor Publik”. Malang: UMM Press

Wicaksono, Agus Dwi \& Budi Sugiarto, 2001. Modul Studio Perencanaan Desa. Malang : Program Studi Perencanaan Wilayah dan Kota Fakultas Teknik Universitas Brawijaya.

Widodo, Ahmad, 2001. "Analisis Pelayanan Publik di Kabupaten Madura (Studi Kasus Pada Pelayanan Kesehatan di Puskesmas Kedundung)". 